\title{
On existence of trends applicable to thermoeconomic optimisation of combined cycle gas turbine power plants
}

\author{
M. Valdés*1, A. Rovira ${ }^{2}$ and M. D. Durán ${ }^{1}$
}

This paper aims at the influence of the nominal power on the design configuration of combined cycle gas turbine (CCGT) power plants. This is achieved by means of a thermoeconomic model aimed at the minimisation of the power plant cost. The present work starts with the establishment of trends in existing commercial gas turbines. Based on these, other trends are found for the design of the whole CCGT, leading to the assessment of the most suitable heat recovery steam generator type and the optimal design parameters. Finally, an analysis of the influence of fuel price on the design configuration is carried out. This serves two purposes: to observe the dependence of economic results with fuel prices and to determine whether fuel price variations might influence the previously established trends in the CCGT design.

Keywords: $\mathrm{CO}_{2}$ taxation, Thermoeconomic optimisation, Combined cycle gas turbine, Heat recovery steam generator

\section{Introduction}

The growing energy demand and the need for cost reduction have led to the design of high efficiency and quick installation power plants. Combined cycle gas turbine (CCGT) power plants fulfill these characteristics, therefore they are undergoing widespread installation and the research in this field has notably increased nowadays. Many contributions may be found in the technical literature aiming at improving the efficiency of the interaction between the gas turbine (GT) and steam turbine (ST) cycles. ${ }^{13}$ A common conclusion of these works is the necessary trade-off between cost and efficiency. This fact has urged many authors to developed thermoeconomic models. However, most of them use these models to solve only particular cases, therefore it is difficult to draw general trends applicable to the majority of cases.

In this paper, a thermoeconomic model described by Valdés et $a l^{4}{ }^{4}$ is employed to verify the existence of trends in the design of CCGT. Six different base cases have been considered: four conventional and two sequential combustion GTs, all of them studied in a number of different optimised CCGT configurations, as described in the section 'Layout of study'. These trends lead to the establishment of the most suitable heat recovery steam generator (HRSG) configuration as a function of the power range, as well as to the assessment of its optimal design parameters from a thermoeconomic point of view.

${ }^{1}$ ETS Ingenieros Industriales, Depto. Ingeniería Energética y Fluidomecánica, C/José Gutiérrez Abascal n 2, 28006 Madrid, España ${ }^{2} \mathrm{ETS}$ Ingenieros Industriales de la UNED, Depto. Ingeniería Energética, C/Juan del Rosal $n^{\circ} 12,28040$ Madrid, España

*Corresponding author, email mvaldes@etsii.upm.es
Because the price of the fuel (together with $\mathrm{CO}_{2}$ taxation in the near future) is the most influential factor in the variable costs of the plant, a sensitivity analysis has been carried out concerning the influence of a possible increase in fuel price on the previously established trends.

\section{Layout of study}

The selection of a particular GT depends upon the desired total power of the CCGT plant. Once it is selected, the temperature and the mass flow of the exhaust gases from the GT determine the subsequent designs of the HRSG and the ST.

Although there are many GTs from different manufacturers, their design parameters -pressure ratio $\pi$, turbine inlet temperature (TIT) and air mass flow $m_{\mathrm{a}}$ and their acquisition cost follow a global trend regardless of the manufacturer, as shown in Figs. 1-3.

Figure 1 shows $\pi$ and TIT as a function of GT power. Points correspond to real gas turbines and lines represent the trends obtained with a linear regression. Two different tendency lines were needed to fit real data: one for high power GTs and the other for low power GTs, being the frontier separating both classes located somewhere between 50 and $80 \mathrm{MW}$. The thick points represent the Alstom GT-24 and GT-26 gas turbines, which do not fit the $\pi$ regression line, because their pressure ratio is higher owing to their special sequential combustion cycle.

Using the above regression lines, the values of $\pi$ and TIT may be estimated as a function of the GT power. With these parameters in hand, the air mass flow that provides the corresponding power may be estimated through

$$
\dot{m}_{\mathrm{a}}=\frac{P_{\mathrm{GT}}}{w_{\mathrm{GT}}}
$$




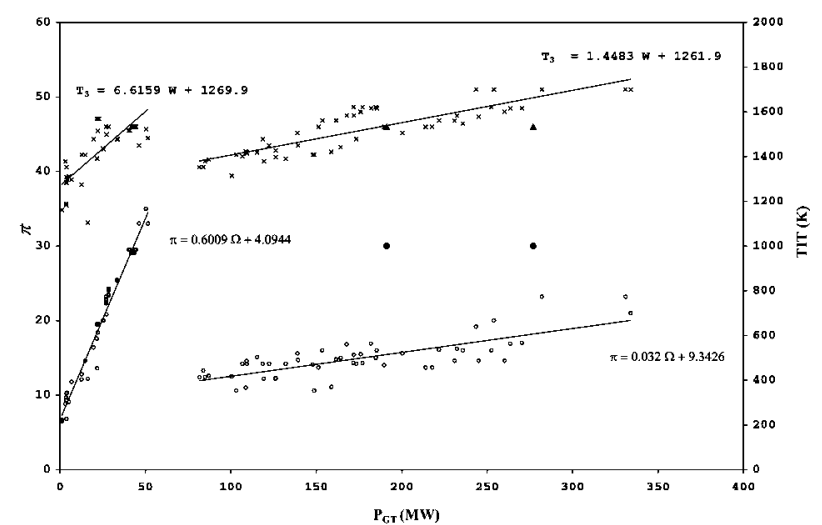

1 Pressure ratio and TIT as function of power for commercial gas turbines

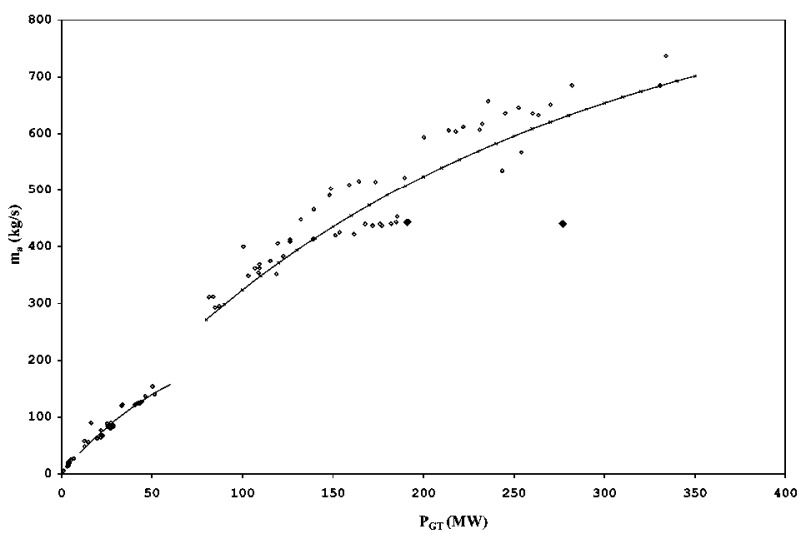

2 Air mass flow for commercial gas turbines (points) and calculated air mass flow for regression equations of Fig. 1 (lines)

where $P_{\mathrm{GT}}$ and $w_{\mathrm{GT}}$ are the power and the specific work output of the gas turbine. The latter mainly depends on $\pi$ and TIT.

The points of Fig. 2 again correspond to real GTs, but in this case the continuous lines represent the air mass flow calculated with equation (1) using $\pi$ and TIT derived from the tendency lines of Fig. 1. The fitting between calculated lines and real cases seems correct, mainly for the high power GTs group where the study focuses on.

Figure 3 shows the acquisition cost (total cost and cost per power unit) trends as a function of GT power. Continuous lines are again regressions of the real GTs represented with points. In this case it may be observed that the Alstom GT-24 and GT-26 fit the regression lines.

The most relevant conclusion of this first analysis is that a 'generic' GT, defined by its main design parameters $\left(\pi\right.$, TIT and $m_{\mathrm{a}}$ ), may be considered for each

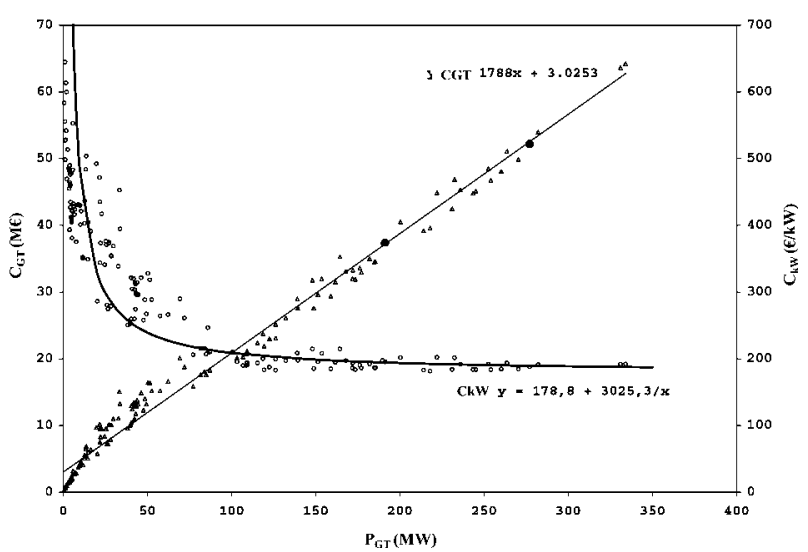

3 Total cost and cost per unit power of commercial gas turbines

desired power and, at the same time, its cost may be plausibly estimated.

In this work, six different gas turbines have been simulated in order to obtain CCGT trends: four 'generic' GTs derived from the tendency lines (with increasing sizes in order to cover a wide range of powers) and the Alstom GT-24 and GT-26. Their design parameters and performances are shown in Table 1.

The following frequently used HRSG configurations were coupled to the above mentioned GTs in order to find the best CCGT solution: single pressure level (1P), dual pressure levels without reheating (2P), dual pressure levels with reheating ( $2 \mathrm{PR})$ and triple pressure levels with intermediate reheating (3PR).

Figure 4 shows the schemes of different HRSG configurations employed.

\section{Thermoeconomic models and optimisation of CCGT}

As it was mentioned before, in the design of CCGT power plants both thermodynamic and economic studies must be carried out. By means of a thermodynamic analysis alone, the most important design parameters and the most relevant sources of irreversibilities may emerge. Improving the CCGT efficiency is usually feasible, but at the expense of an increase in the total cost of the plant. Thermoeconomic analyses intend to achieve a trade-off between high efficiency and acceptable cost. Several works regarding this field of research can be found in the literature. El-Sayed, 5,6 Frangopoulos ${ }^{7,8}$, Valero et $a l^{9}$ and Tsatsaronis ${ }^{10}$ proposed models based on a breaking down of the elements of the plant so that a cost may be assigned to each exergy flow. These models have been used in other works. ${ }^{11}$ They are valuable in a wide range of different applications, particularly in cogeneration systems, where

Table 1 Design parameters and performances of gas turbines used

\begin{tabular}{|c|c|c|c|c|c|}
\hline Gas turbine & TIT, $\mathrm{K}$ & $\pi$ & $m_{\mathrm{a}}, \mathrm{kg} \mathrm{s}^{-1}$ & $P_{\mathrm{GT}}, \mathrm{MW}$ & $T_{\text {exhGT, }}, \mathrm{K}$ \\
\hline 1 & 1378 & $11 \cdot 9$ & $271 \cdot 3$ & 80 & 833 \\
\hline 2 & 1479 & $14 \cdot 1$ & $435 \cdot 2$ & 150 & 870 \\
\hline 3 & 1624 & $17 \cdot 3$ & $595 \cdot 7$ & 250 & 927 \\
\hline 4 & 1769 & $20 \cdot 5$ & $701 \cdot 6$ & 350 & 988 \\
\hline GT-24 & 1533 & 30 & 381 & 191 & 914 \\
\hline GT-26 & 1533 & 30 & 549 & 277 & 914 \\
\hline
\end{tabular}


(a)

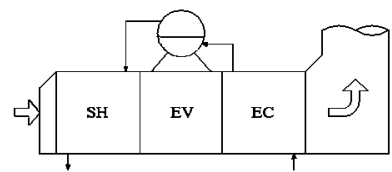

(b)

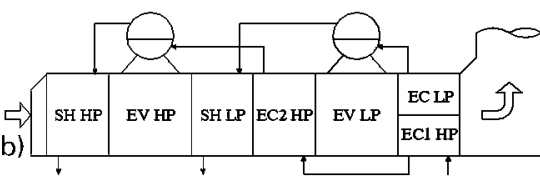

(c)
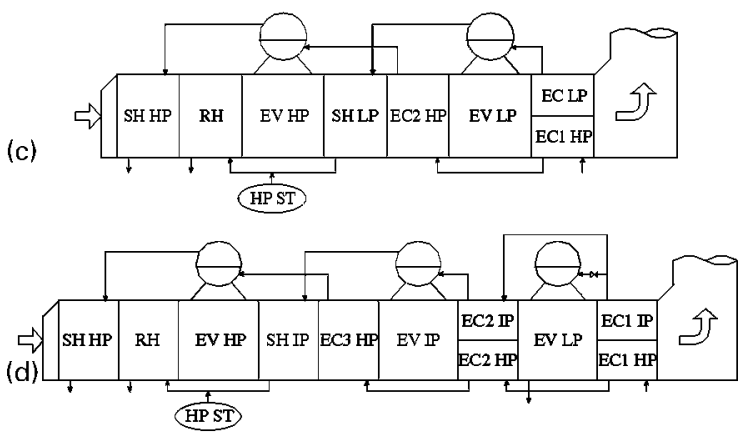

a 1P; b 2P; c 2PR; $d$ 3PR

4 Schemes of HRSG configurations

the cost of several products (heat and power) should be assessed. With regard to CCGT analysis, other models have also been developed. For example, Franco and Russo $^{12}$ and Liszka et al. ${ }^{13}$ made a thermoeconomic study focused on the HRSG, and Dechamps ${ }^{14}$ developed a methodology based on marginal costs in order to reach a trade-off between efficiency and generation cost.

The model used in this paper has been developed in previous works. ${ }^{4,15,16}$ Its objective is the minimisation of the generation cost of the CCGT, although other optimisation methodologies like the maximisation of the plant cash flow may be used. The main equations lying within the model are briefly outlined in 'Appendix'.

The aim of this study is to establish whether there is a trend in the design of CCGT plants as a function of the power of the plant. For that purpose, an optimisation methodology is required in order to determine the most suitable HRSG and steam cycle for each selected GT.

Optimisation problems in thermal engineering usually deal with non-linear equations that depend on many variables and constrains. There are several optimisation methodologies to solve these problems. ${ }^{17}$ This work employs the genetic algorithm proposed by Valdes et al. $^{20}$ to carry out a thermoeconomic optimisation. Genetic algorithms have been previously applied to similar problems with good results by other authors. ${ }^{21} 23$

The set of independent variables subjected to the optimisation process comprises drum pressure $p$, pinch point (PP), approach point (AP) and steam temperature at each pressure level of the HRSG (HP, IP and LP). At the same time, the methodology takes into account some restrictions imposed to the moisture at the exit of the steam turbine and to the temperature of the gases at the HRSG exhaust.

\section{Results}

Tables 2-5 show the design parameters as well as power $P_{\mathrm{CC}}$, efficiency $\eta_{\mathrm{CC}}$, cash flow (CF) and cost for minimum cost optimisation $C_{\mathrm{kwh}}$ of different HRSG configurations coupled to the GTs defined in Table 1.

These data have been represented in Figs. 5-7 in order to establish the HRSG configuration with the best thermoeconomic results.

Figure 5 compares the efficiency of different HRSG configurations with increasing CCGT power. The 3PR case is the best configuration from $\sim 250 \mathrm{MW}$ upwards,

Table 2 Optimisation of $1 \mathrm{P}$ configuration

\begin{tabular}{|c|c|c|c|c|c|c|c|}
\hline Gas turbine & $p$, bar & $\mathrm{PP}, \mathrm{K}$ & $\mathrm{AP}, \mathrm{K}$ & $P_{\mathrm{cc}}, \mathrm{MW}$ & $\eta_{\mathrm{cc}}$ & $\mathrm{CF}, \mathrm{M} \in$ & $C_{k w h}, c €$ \\
\hline 1 & $106 \cdot 6$ & $4 \cdot 0$ & 3.0 & 128 & 0.498 & 0.66 & $3 \cdot 82$ \\
\hline 2 & $175 \cdot 9$ & $4 \cdot 0$ & 30 & 245 & 0.534 & 4.94 & 3.53 \\
\hline 3 & 180 & 4.0 & $3 \cdot 0$ & 417 & 0.573 & 14.08 & $3 \cdot 31$ \\
\hline 4 & 180 & $8 \cdot 4$ & 30 & 590 & 0.599 & $24 \cdot 80$ & $3 \cdot 17$ \\
\hline GT-24 & 180 & 4.0 & $3 \cdot 0$ & 284 & 0.572 & $10 \cdot 82$ & $3 \cdot 34$ \\
\hline GT-26 & 180 & $4 \cdot 0$ & 30 & 409 & 0.572 & $16 \cdot 50$ & $3 \cdot 31$ \\
\hline
\end{tabular}

Table 3 Optimisation of $2 \mathrm{P}$ configuration

\begin{tabular}{|c|c|c|c|c|c|c|c|c|c|c|}
\hline Gas turbine & $p_{\mathrm{HP}}$, bar & $\mathrm{PP}_{\mathrm{HP}}, \mathrm{K}$ & $\mathrm{AP}_{\mathrm{HP}}, \mathrm{K}$ & $p_{\mathrm{LP}}, \mathrm{bar}$ & $\mathrm{PP}_{\mathrm{LP}}, \mathrm{K}$ & $A P_{L P}, K$ & $P_{\mathrm{cc}}, \mathrm{MW}$ & $\eta_{\mathrm{cc}}$ & $\mathrm{CF}, \mathrm{M} \in$ & $C_{\mathrm{kwh}}, \mathrm{c} €$ \\
\hline 1 & $124 \cdot 7$ & 6.0 & $3 \cdot 0$ & $4 \cdot 4$ & $12 \cdot 0$ & $3 \cdot 0$ & 135 & 0.525 & $1 \cdot 84$ & $3 \cdot 69$ \\
\hline 2 & $133 \cdot 1$ & $5 \cdot 9$ & $3 \cdot 4$ & $5 \cdot 2$ & $9 \cdot 7$ & $4 \cdot 9$ & 253 & 0.549 & $7 \cdot 36$ & $3 \cdot 47$ \\
\hline 3 & $134 \cdot 6$ & 6.9 & $3 \cdot 5$ & 6.5 & $5 \cdot 7$ & $3 \cdot 0$ & 421 & 0.578 & $17 \cdot 09$ & $3 \cdot 29$ \\
\hline 4 & $136 \cdot 7$ & $11 \cdot 1$ & $3 \cdot 6$ & $8 \cdot 3$ & $12 \cdot 0$ & $7 \cdot 7$ & 594 & 0.601 & $28 \cdot 72$ & $3 \cdot 16$ \\
\hline GT-24 & $103 \cdot 0$ & 6.2 & $8 \cdot 0$ & $5 \cdot 3$ & 6.0 & $3 \cdot 0$ & 285 & 0.571 & $10 \cdot 73$ & $3 \cdot 36$ \\
\hline GT-26 & $99 \cdot 7$ & 6.0 & $6 \cdot 4$ & $4 \cdot 5$ & $10 \cdot 5$ & $6 \cdot 1$ & 410 & 0.571 & $16 \cdot 36$ & $3 \cdot 32$ \\
\hline
\end{tabular}

Table 4 Optimisation of 2PR configuration

\begin{tabular}{|c|c|c|c|c|c|c|c|c|c|c|}
\hline Gas turbine & $p_{\mathrm{HP}}$, bar & $\mathrm{PP}_{\mathrm{HP}}, \mathrm{K}$ & $A P_{H P}, K$ & $p_{\mathrm{LP}}, \mathrm{bar}$ & $P P_{L P}, K$ & $A P_{L P}, K$ & $P_{\mathrm{CG}}, \mathrm{MW}$ & $\eta_{\mathrm{GC}}$ & $\mathrm{CF}, \mathrm{M} \in$ & $C_{\mathrm{kwh}}, \mathrm{c} €$ \\
\hline 1 & $82 \cdot 1$ & $9 \cdot 7$ & $4 \cdot 9$ & $3 \cdot 9$ & $5 \cdot 2$ & $3 \cdot 1$ & 133 & 0.517 & $1 \cdot 31$ & $3 \cdot 74$ \\
\hline 2 & $100 \cdot 7$ & $10 \cdot 5$ & $4 \cdot 4$ & $4 \cdot 5$ & $4 \cdot 9$ & $3 \cdot 1$ & 250 & 0.542 & 6.55 & $3 \cdot 51$ \\
\hline 3 & $147 \cdot 8$ & $11 \cdot 3$ & $4 \cdot 0$ & $5 \cdot 8$ & $5 \cdot 1$ & $3 \cdot 2$ & 421 & 0.576 & $17 \cdot 3$ & $3 \cdot 31$ \\
\hline 4 & 180 & $11 \cdot 6$ & $4 \cdot 0$ & 6.6 & $5 \cdot 4$ & $5 \cdot 8$ & 600 & 0.604 & $30 \cdot 4$ & $3 \cdot 16$ \\
\hline GT-24 & $145 \cdot 5$ & $11 \cdot 6$ & $4 \cdot 1$ & 6.0 & $5 \cdot 1$ & $3 \cdot 2$ & 286 & 0.574 & $10 \cdot 71$ & $3 \cdot 35$ \\
\hline GT-26 & $143 \cdot 7$ & $9 \cdot 9$ & $4 \cdot 2$ & $5 \cdot 8$ & $5 \cdot 6$ & $3 \cdot 0$ & 413 & 0.574 & $16 \cdot 36$ & $3 \cdot 31$ \\
\hline
\end{tabular}




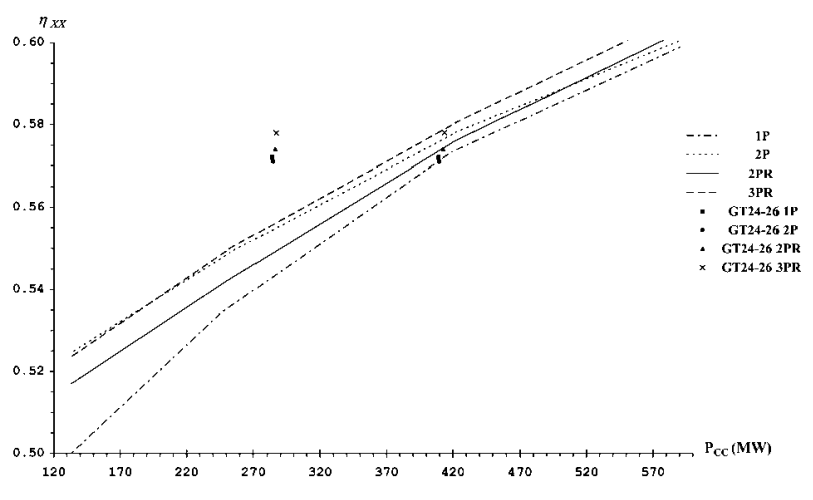

5 Efficiency of optimised CCGT

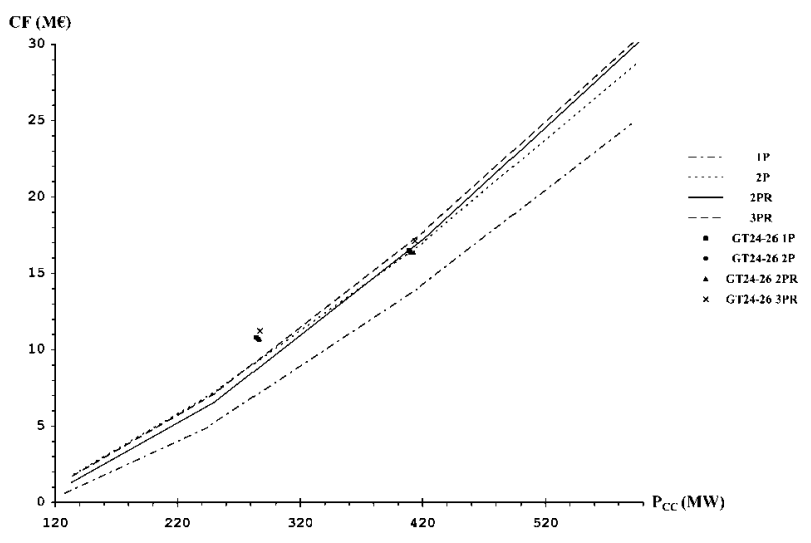

6 Annual cash flow of optimised CCGT

while less than $250 \mathrm{MW}$ the $2 \mathrm{P}$ case is better. The $1 \mathrm{P}$ configuration obtained the worst results for the whole range of powers studied.

Figures 6 and 7 show the evolution of the cash flow and the generation cost for different HRSG configurations as the power of the CCGT increases. It is interesting to point out the little difference in cash flow and generation cost between the $2 \mathrm{PR}$ and $3 \mathrm{PR}$ configurations. This is because that although the 3PR has better efficiency, its acquisition cost is higher than that of the 2PR. Also, it may be observed that, for powers $<320 \mathrm{MW}$, the best results are obtained for the $2 \mathrm{P}$ configuration, while at higher powers the best configuration is again the 3PR one.

Figures 5-7 also show the efficiency, cash flow and generation cost of the configurations coupled to the Alstom GT-24 and GT-26 gas turbines. The results obtained for the GT-24 case are better than those predicted by the trend line, while there is not much difference for the GT-26. This behaviour is caused by the exhaust temperature (see Table 1). For the GT-24 case, this parameter is higher than that for a conventional GT of the same nominal power, while for the GT26 case they are similar.

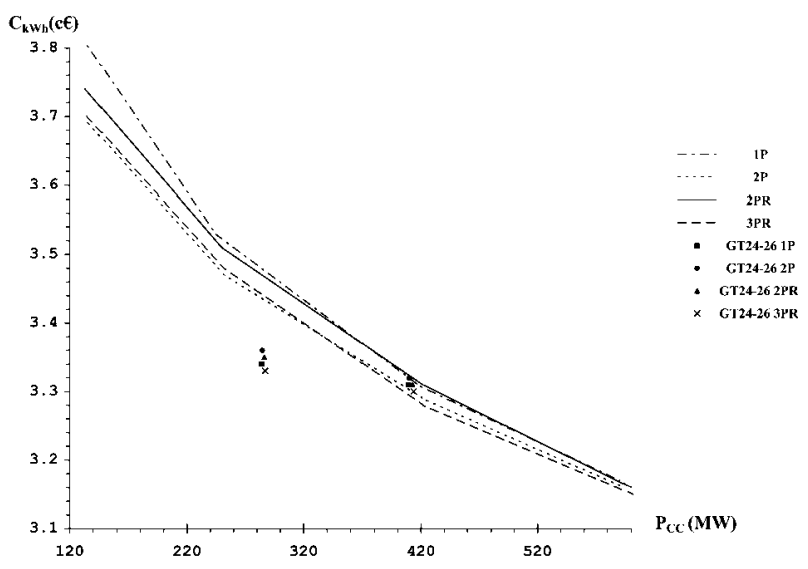

7 Generation cost of optimised CCGT

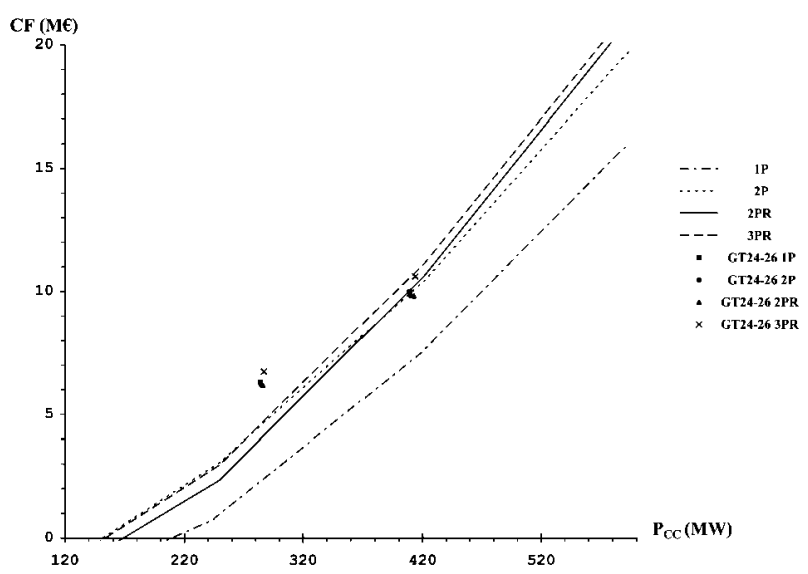

8 Annual cash flow of optimised CCGT when fuel price is $10 \%$ higher

Finally, the influence of the fuel price is shown in Fig. 8. This graph is equivalent to Fig. 6, but evaluating the cash flow when the fuel price has increased by $10 \%$. In this case, the 3PR configuration is the most suitable one for powers of $280 \mathrm{MW}$ onwards, instead of the before mentioned $320 \mathrm{MW}$. This means that, when the fuel price increases, better thermoeconomic results are achieved as more efficient the CCGT power plant is. Therefore, it is advisable to select high efficiency HRSG configurations, so that economic results are less unstable if an increasing fuel price scenario is expected. The same behaviour applies when $\mathrm{CO}_{2}$ taxations are considered instead of an increase in fuel price.

\section{Conclusions}

In this work, a thermoeconomic analysis of CCGT power plants that enables the extraction of some trends in CCGT design was carried out. These trends established the most suitable HRSG configurations

Table 5 Optimisation of 3PR configuration

\begin{tabular}{|c|c|c|c|c|c|c|c|c|c|c|c|c|c|}
\hline $\begin{array}{l}\text { Gas } \\
\text { turbine }\end{array}$ & $\begin{array}{l}p_{\mathrm{HP}} \\
\mathrm{bar}\end{array}$ & $\begin{array}{l}\mathrm{PP}_{\mathrm{HP}} \text {, } \\
\mathrm{K}\end{array}$ & $\begin{array}{l}\mathrm{AP}_{\mathrm{HP}}, \\
\mathrm{K}\end{array}$ & $\begin{array}{l}p_{\mathrm{IP}} \\
\mathrm{bar}\end{array}$ & $\begin{array}{l}\mathrm{PP}_{\mathrm{IP}} \text {, } \\
\mathrm{K}\end{array}$ & $\begin{array}{l}\mathrm{AP}_{\mathrm{IP}} \text {, } \\
\mathrm{K}\end{array}$ & $\begin{array}{l}p_{\mathrm{LP}} \\
\text { bar }\end{array}$ & $\begin{array}{l}\mathrm{PP}_{\mathrm{LP}} \text {, } \\
\mathrm{K}\end{array}$ & $\begin{array}{l}A P_{L P}, \\
K\end{array}$ & $\begin{array}{l}\mathbf{P}_{\mathrm{CC}} \\
\mathrm{MW}\end{array}$ & $\eta_{\mathrm{CC}}$ & $\begin{array}{l}\mathrm{CF} \\
\mathrm{M} \in\end{array}$ & $\begin{array}{l}C_{\mathrm{kwh}}, \\
\mathrm{c} \in\end{array}$ \\
\hline 1 & 180 & $12 \cdot 9$ & $3 \cdot 0$ & $23 \cdot 7$ & $7 \cdot 7$ & 3.0 & 3.0 & 9.0 & 3.0 & 134 & 0.524 & $1 \cdot 72$ & $3 \cdot 70$ \\
\hline 2 & 180 & $11 \cdot 8$ & $3 \cdot 0$ & $23 \cdot 8$ & $7 \cdot 4$ & $3 \cdot 0$ & 3.6 & $7 \cdot 2$ & $3 \cdot 0$ & 252 & 0.550 & $7 \cdot 23$ & $3 \cdot 48$ \\
\hline 3 & 180 & $12 \cdot 6$ & $3 \cdot 1$ & $17 \cdot 9$ & 8.8 & $3 \cdot 7$ & $3 \cdot 6$ & 8.0 & $7 \cdot 8$ & 439 & 0.580 & $17 \cdot 48$ & $3 \cdot 28$ \\
\hline 4 & 180 & $9 \cdot 1$ & $3 \cdot 0$ & $20 \cdot 4$ & $8 \cdot 7$ & $10 \cdot 6$ & 4.5 & $5 \cdot 6$ & $3 \cdot 0$ & 601 & 0.608 & $30 \cdot 84$ & $3 \cdot 15$ \\
\hline GT-24 & 180 & $10 \cdot 6$ & $3 \cdot 0$ & $23 \cdot 8$ & 9.5 & $9 \cdot 6$ & 4.0 & 6.0 & $4 \cdot 1$ & 287 & 0.578 & $11 \cdot 25$ & $3 \cdot 33$ \\
\hline GT-26 & 180 & 8.7 & $3 \cdot 1$ & $23 \cdot 2$ & 12.5 & $7 \cdot 6$ & 4.0 & $5 \cdot 6$ & $3 \cdot 1$ & 414 & 0.578 & $17 \cdot 12$ & $3 \cdot 30$ \\
\hline
\end{tabular}




\begin{tabular}{lll}
\hline$h=7000 \mathrm{~h} /$ year & $N=15$ years & $C_{1 \mathrm{GT}}=0.1788 \mathrm{M} € / \mathrm{MW}$ \\
$P=3.89 \mathrm{c} \in / \mathrm{kWh}$ & $K_{\mathrm{ec}}=2500 € /(\mathrm{kW} \mathrm{K})^{0.8}$ & $C_{2 \mathrm{GT}}=3.0253 \mathrm{M} €$ \\
$F=1.30 \mathrm{c} € / \mathrm{kWh}$ & $K_{\mathrm{ev}}=4000 € /(\mathrm{kW} \mathrm{K})^{0.8}$ & $C_{1 \mathrm{sT}}=0.115 \mathrm{M} € / \mathrm{MW}$ \\
$i=0.10$ & $K_{\mathrm{sh}}=8000 € /(\mathrm{kW} \mathrm{K})^{0.8}$ & $C_{2 \mathrm{st}}=2.75 \mathrm{M} €$ \\
\hline
\end{tabular}

and the value of their design parameters depending on the power of the plant.

The most important conclusion is that it is possible to find the range of power where a HRSG configuration is optimal using a thermoeconomic model and an optimisation tool. For the power interval studied, the dual pressure level CCGT is more convenient for medium power, while the triple pressure level with reheating is preferable at high powers. With the data and the assumptions employed in this work, the frontier may be located at $320 \mathrm{MW}$. The worst HRSG configuration is the single pressure one.

Another conclusion of the work is that turbines with higher exhaust temperatures than the average ones (for each nominal power) lead to better economic results, as the particular case of the Alstom GT-24 gas turbine shows.

Finally, an analysis regarding the influence of the fuel price (or $\mathrm{CO}_{2}$ taxation) has been carried out. It shows that more efficient CCGT power plants obtain better thermoeconomic results when the fuel price increases. For this reason, in order to obtain similar economic results, it is convenient to select higher efficiency HRSG configurations.

\section{Appendix}

The annual cash flow $B$ of the power plant is

$$
B=I_{\text {Tot }}-C_{\text {Tot }}
$$

the total income $I_{\text {Tot }}$ in the equation (2) is defined by

$$
I_{\mathrm{Tot}}=S \cdot \bar{W} \cdot h
$$

where $S$ is the selling price of the energy to the grid, $\bar{W}$ is the mean power of the CCGT and $h$ is the plant working hours per year.

The total cost per year $C_{\text {Tot }}$ in the equation (2) is

$$
C_{\text {Tot }}=C_{\mathrm{tf}}+C_{\mathrm{a}}+C_{\mathrm{om}}
$$

where $C_{\text {tf }}$ is the total fuel cost, which is a function of the plant efficiency $\eta$ and the fuel price $C_{\mathrm{f}}$

$$
C_{\mathrm{tf}}=C_{\mathrm{f}} \cdot\left(\frac{\bar{W}}{\eta}\right) \cdot h
$$

$C_{\mathrm{a}}$ is the amortisation cost

$$
C_{\mathrm{a}}=2 \beta\left(C_{\mathrm{GT}}+C_{\mathrm{HRSG}}+C_{\mathrm{ST}}\right)
$$

where, for the discount rate $i$ and the economic life of the plant $N$

$$
\beta=\frac{i \cdot(1+i)^{\mathrm{N}}}{(1+i)^{\mathrm{N}}-1}
$$

the cost of the gas turbine is obtained from the regression lines of Fig. 3

$$
C_{\mathrm{GT}}=C_{1 \mathrm{GT}} \cdot W_{\mathrm{GT}}+C_{2 \mathrm{GT}}
$$

and, similarly for the steam turbine cost

$$
C_{\mathrm{ST}}=C_{1 \mathrm{ST}} \cdot W_{\mathrm{ST}}+C_{2 \mathrm{ST}}
$$

where $C_{1}$ and $C_{2}$ are coefficients given in Table 6 .

Considering three different types of sections (economisers, evaporators and superheaters) the cost of the HRSG surface is

$$
\begin{aligned}
C_{\mathrm{HRSG}}= & \sum_{\mathrm{ec}} K_{\mathrm{ec}} \cdot U A_{\mathrm{ec}}^{0.8}+\sum_{\mathrm{ev}} K_{\mathrm{ev}} \cdot U A_{\mathrm{ev}}^{0 \cdot 8}+ \\
& \sum_{\mathrm{sh}} K_{\mathrm{sh}} \cdot U A_{\mathrm{sh}}^{0.8}
\end{aligned}
$$

where $U$ is the global coefficient of heat transfer, $A$ the heat transfer section area and $K$ is a coefficient given in Table 6.

$C_{\mathrm{om}}$ is the operation and maintenance cost which is considered to be $10 \%$ of the total plant cost

$$
C_{\mathrm{om}}=\frac{C_{\mathrm{Tot}}}{10}
$$

finally, the generation cost $C_{\mathrm{kWh}}$ is the total cost per year divided by the mean annual energy output

$$
C_{\mathrm{kWh}}=\frac{C_{\mathrm{Tot}}}{\bar{W} \cdot h}
$$

\section{Acknowledgement}

The authors wish to acknowledge the financial support from ENDESA to this work.

\section{References}

1. J. H. Horlock: 'Combined power plants', 1st edn; 1992, Oxford, Pergamon Press.

2. R. Kehlhofer, J. Warner, H. Nielsen and R. Bachmann: 'Combined cycle gas-steam turbine power plants', 2nd edn; 1999, Tulsa, OK, PennWell.

3. G. Cerri: Trans. ASME, 1987, 109, (1), 46-54

4. M. Valdés, A. Rovira and M. D. Durán: Int. J. Energ. Res., 2004, 28, (14), 1255-1267.

5. Y. M. El-Sayed: Trans. ASME, J. Eng. Gas Turb. Power, 1996, 118, (4), 693-697

6. Y. M. El-Sayed: Trans. ASME, J. Eng. Gas Turb. Power, 1996, 118 (4), 698-703.

7. C. A. Frangopoulos: Energy, 1987, 12, (7), 563-571.

8. C. A. Frangopoulos: Energy, 1988, 13, (3), 239-244

9. A. Valero, M. A. Lozano, L. Serra and C. Torres: Energy, 1994, 19, (3), 365-381.

10. G. Tsatsaronis: Prog. Energ. Combust. Sci., 1993, 19, 227-257.

11. A. Agazzani and A. F. Massardo: Trans. ASME, 1997, 119, (4), $885-892$.

12. A. Franco and A. Russo: Int. J. Therm. Sci., 2002, 41, 843-859.

13. M. Liszka, G. Manfrida and A. Ziebik: Energ. Convers. Manag., $2003,44,(7), 995-1012$.

14. P. J. Dechamps: Proc. ASME Cogen-Turbo Power Generation, Vienna, Austria, August 1995, ASME, Paper 95-CTP-101.

15. A. Rovira: 'Desarrollo de un modelo par la caracterización termoeconómica de ciclos combinados de turbinas de gas y de vapor en condiciones de carga variable', $\mathrm{PhD}$ thesis, Universidad Politécnica de Madrid, Madrid, Spain, 2004.

16. M. D. Durán: 'Estudio de calderas de recuperación de calor de ciclos combinados de turbinas de gas y vapor empleando la técnica de algoritmos genéticos', $\mathrm{PhD}$ thesis, Universidad Politécnica de Madrid, Madrid, Spain, 2004 
17. W. F. Stoecker: 'Design of thermal systems', 3rd edn; 1989, New York, McGraw-Hill.

18. K. Deb: 'Optimization for engineering design: algorithms and examples'; 1995, New Delhi, Prentice-Hall.

19. G. V. Reklaitis, A. Ravindran and K. M. Ragsdell: 'Engineering optimization methods and applications'; 1993, New York, Wiley.
20. M. Valdés, M. D. Durán and A. Rovira: Appl. Therm. Eng., 2003, 23, (17), 2169-2182

21. G. Fabbri: Int. J. Heat. Fluid Flow, 1998, 19, 644654.

22. L. Attala, B. Facchini and G. Ferrara: Energ. Convers. Manag., 2001, 42, 2163-2172.

23. A. Toffolo and A. Lazzaretto: Energy, 2002, 27, 549-567. 